\title{
DIALOGANDO COM PAULO FREIRE E MARIELLE FRANCO: UM MANIFESTO POÉTICO ATRAVÉS DE UMA PERFORMANCE AUDIOVISUAL
}

\author{
DIALOGUE WITH PAULO FREIRE AND MARIELLE FRANCO: \\ A POETIC MANIFESTO THROUGH AN AUDIOVISUAL PERFORMANCE
}

\section{DIÁLOGO CON PAULO FREIRE Y MARIELLE FRANCO: UN MANIFIESTO POÉTICO A TRAVÉS DE UNA ACTUACIÓN AUDIOVISUAL}

\author{
Bianca de Menezes Castro da Silva ${ }^{1}$ \\ Danielle Christina do Nascimento Oliveira ${ }^{2}$
}

\begin{abstract}
RESUMO
Neste artigo, apresentaremos um diálogo subjetivo entre dois personagens emblemáticos na atualidade, com corpos em fricção: Paulo Freire e Marielle Franco, que teve como objetivo a produção artística e cultural através da performance audiovisual com um manifesto poético sobre os pensamentos do primeiro e a vida da segunda, a partir da "metodologia do encontro". O resultado deste trabalho foi a potência do encontro entre o simbólico de Marielle Franco e a perspectiva de Paulo Freire, nos demonstrando o quanto (sobre)viver é um ato político! Estes personagens deixaram suas vidas e obras como legado, ou melhor dizendo, sementes.
\end{abstract}

PALAVRAS-CHAVE: Política. Produção Estética. Redes de conhecimentos.

\begin{abstract}
In this article, we will present a subjective dialogue between two emblematic characters today, with bodies in friction: Paulo Freire and Marielle Franco, whose objective was the artistic and cultural production through audiovisual performance with a poetic manifesto about the thoughts of the former and life gives second, from the "meeting methodology". The result of this work was the power of the encounter between the symbolic of Marielle Franco and the perspective of Paulo Freire, showing us how much (on) living is a political act! These characters left their lives and works as a legacy, or rather, seeds.
\end{abstract}

KEYWORDS: Policy. Aesthetic Production. Knowledge networks.

\section{RESUMEN}

En este artículo presentaremos un diálogo subjetivo entre dos personajes emblemáticos de la actualidad, con cuerpos en fricción: Paulo Freire y Marielle Franco, cuyo objetivo era la producción artística y cultural a través

Submetido em: 10/08/2021 - Aceito em: 29/08/2021 - Publicado em: 13/10/2021

\begin{abstract}
${ }^{1}$ Mestre em Educação pelo Programa de Pós-graduação em Educação (ProPEd-UERJ), licenciada em Pedagogia pela Faculdade de Educação (UERJ) e Professora da Educação Básica no Município do Rio de Janeiro - Anos Iniciais. Lattes: http://lattes.cnpq.br/0621295774636679 E-mail: biancamenezescastro@ hotmail.com

${ }^{2}$ Mestra em Educação pelo Programa de Pós-graduação em Educação (ProPEd-UERJ), licenciada em Pedagogia pela Faculdade de Educação (UERJ), especialista em Educação das Relações Étnico-Raciais no Ensino Básico pelo Colégio Pedro II; e Professora substituta da Educação Infantil do Colégio de Aplicação da Universidade Federal do Rio de Janeiro (CAp UFRJ); Membro do Grupo de Pesquisas Culturas e Identidades no Cotidiano (ProPEd-UERJ) e do Grupo de Estudos e Extensão Currículo em Movimento na Educação Infantil (CEIMOVUFRJ). Lattes: http://lattes.cnpq.br/7439626178933819 E-mail: danielle.danichris@ hotmail.com
\end{abstract}




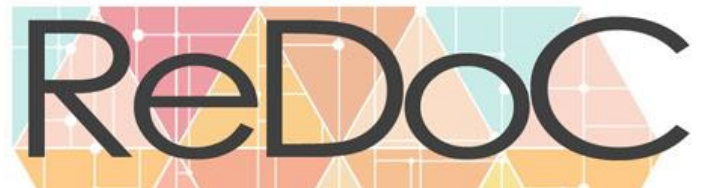

\section{Revista Docência e Cibercultura}

de la performance audiovisual con un manifiesto poético sobre el pensamiento del primero y la vida. da en segundo lugar, de la "metodología de reuniones". El resultado de este trabajo fue la fuerza del encuentro entre lo simbólico de Marielle Franco y la perspectiva de Paulo Freire, ¡mostrándonos cuánto (de) vivir es un acto político! Estos personajes dejaron sus vidas y obras como legado, o mejor dicho, como semillas.

PALABRAS CLAVE: Política. Producción estética. Redes de conocimiento.

\section{INTRODUÇÃO}

O que faz efetivamente um corpo? O olhar sobre um corpo investe em sua superfície, percebido como um organismo semelhante ao outro que respira. Para a fisiologia somos este componente biológico repleto de células, tecidos e órgãos. No entanto, nessa mesma superfície usufruímos da habilidade de enumerar traços físicos que nos constituem no jogo de aproximação e distanciamento dos corpos sociais outorgados e dos corpos sociais marginalizados. Emerge nesse jogo, a dimensão simbólica que inunda o corpo, inaugurando o ato de caracterizar e, principalmente, interpretar. Como o antropólogo francês Jean-Jacques Courtine (2013) assinala, "[...] a fisiognomonia são maneiras de dizer e de ver o corpo humano (p. 48)", em termos de exterioridade, aparência que envolve o corpo, sem, contudo, alcançar a totalidade da complexidade singular de cada sujeito.

O processo de conceber um corpo está envolvido por uma arqueologia discursiva, enunciada por dispositivos de poder (FOUCAULT, 1987). No vasto campo informacional de condutas há a dissolução do corpo, ou seja, os discursos modernos apresentam à sociedade a precariedade e o descrédito do corpo, o qual se considera necessitado de dominação. Contudo, toda ideia e discurso se origina em um corpo e são atravessados e até conduzidos por suas experiências sensoriais e sensíveis. Portanto, nenhuma certeza aplicada ao corpo capta a rede de vivências que o corpo denominado ou etiquetado acumula.

A modernidade criou artifícios discursivos que garantiriam a hegemonia na produção de todo tipo de postulados, normas e leis, sob as quais o corpo foi separado do pensamento e desacreditado como meio de ler e criar o mundo. O autor alemão Hans Ulrich Gumbrecht (2010) nomeia essa visão de mundo de hermenêutica, um subcampo filosófico que possui técnicas e condições de interpretação do que crê existir. Nessa mesma rota estaria a hierarquização dicotômica dos corpos, o corpo verdadeiro e o corpo primitivo. De um lado, um corpo iluminado pelo conhecimento moderno, do outro um corpo errático nas sensações e atribuidor de corporeidade às formas que se mesclam a ele.

Os discursos de coerção circulam sobre os corpos para reeducar, higienizar, padronizar e marginalizar. A partir dos estudos de Paulo Freire ${ }^{3}$ - patrono da educação brasileira -, compreendemos que a educação

\footnotetext{
${ }^{3}$ Paulo Freire nasceu em 19 de setembro de 1921 e faleceu em 02 de maio de 1997, vítima de um ataque cardíaco. Graduado pela Faculdade de Direito de Recife-PE, foi professor de Língua Portuguesa do Colégio Oswaldo Cruz e diretor do setor de Educação e Cultura do SESI e superintendente do mesmo. Ao lado de outros educadores e pessoas interessadas na educação escolarizada, fundou o Instituto Capibaribe. Sua filosofia educacional expressouse primeiramente em 1958 na sua tese de concurso para a Universidade do Recife, e, mais tarde, como professor de História e Filosofia da Educação da mesma, bem como em suas primeiras experiências de alfabetização como a de Angicos, Rio Grande do Norte, em 1963. Em 1969, foi professor na Universidade de Harvard, em estreita colaboração com numerosos grupos engajados em novas experiências educacionais tanto em zonas rurais quanto urbanas. Durante os dez anos seguintes, foi Consultor Especial do Departamento de Educação do Conselho Mundial das Igrejas, em Genebra (Suíça). Nesse período, deu consultoria educacional junto a vários governos do Terceiro Mundo, principalmente na África. Em 1980, depois de 16 anos de exílio, retornou ao Brasil para 


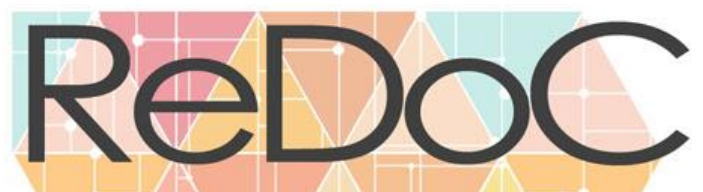

\section{Revista Docência e Cibercultura}

bancária, na qual ele acredita que o professor vê o educando como um banco, ou seja, local de depósito do conhecimento, doméstica e oprime para uma realidade exclusiva e excludente, quando o ser humano caminha sobre estes moldes sociais seu corpo é atravessado por amarras de opressão. No entanto, o confronto do corpo em ter o prazer e domínio de si mergulhado na complexidade cotidiana estabelece novos caminhos de autonomia. Por isso, o conhecimento que visa nos oprimir terá sua ruptura em nós. Práticas de autonomia incentivadas por Paulo Freire no cotidiano das vidas podem e devem romper com as hierarquias.

Um corpo em atrito - do qual trataremos aqui, e que foi (re)produzido em uma performance audiovisual ${ }^{4}$ que estimulou a elaboração deste trabalho -, traz consigo problemáticas históricas, sociais e políticas, que reverberaram ainda mais neste período pandêmico, nos demonstrando quais são os corpos que tem direito a vida, no seu sentido pleno, como descrito no Artigo $227^{\circ}$ da Constituição Federal de 1988:

É dever da família, da sociedade e do Estado assegurar à criança, ao adolescente e ao jovem, com absoluta prioridade, o direito à vida, à saúde, à alimentação, à educação, ao lazer, à profissionalização, à cultura, à dignidade, ao respeito, à liberdade e à convivência familiar e comunitária, além de colocá-los a salvo de toda forma de negligência, discriminação, exploração, violência, crueldade e opressão. (BRASIL, 1988).

Apesar desses serem direitos sociais, o corpo de Marielle Franco ${ }^{5}$, bem como o de tantas pessoas negras não têm esses direitos assegurados. No Brasil, as desigualdades têm raça, cor, etnia e classe social, pois

"reaprender" seu país. Lecionou na Universidade Estadual de Campinas (UNICAMP) e na Pontifícia Universidade Católica de São Paulo. Em 1989, tornou-se Secretário de Educação no Município de São Paulo, e lutou pela implementação de movimentos de alfabetização, de revisão curricular e na recuperação salarial dos professores. Em 1964, no Chile, desenvolveu, durante cinco anos, trabalhos em programas de educação de adultos no Instituto Chileno para a Reforma Agrária (ICIRA). Paulo Freire é autor de muitas obras, e foi reconhecido mundialmente pela sua práxis educativa através de numerosas homenagens. Além de ter seu nome adotado por muitas instituições, é cidadão honorário de várias cidades no Brasil e no exterior (comunidade freiriana). A Paulo Freire foi outorgado o título de doutor Honoris Causa por 27 universidades. É o Patrono da Educação Brasileira (2013). Disponível em:< https://www.paulofreire.org/o-instituto-paulo-freire $>$. Acesso em: 29 ago. 2021.

${ }^{4} \mathrm{O}$ vídeo da performance audiovisual do qual este artigo trata, está publicado no site Revista Duas Cabeças (2020). Disponível em:<https://www.revistaduascabecas.org/corposemfriccao >. Acesso em 29 de ago. 2021.

${ }^{5}$ Marielle Franco nasceu em 27 de julho de 1979 e foi executada com três tiros na cabeça e um no pescoço, dia 14 de março de 2018, junto com o também assassinado, Anderson Gomes, motorista do veículo que a vereadora se encontrava no retorno de um compromisso político na Casa das Pretas - RJ. Marielle é cria da favela da Maré, socióloga formada pela PUC-Rio e mestra em Administração Pública pela Universidade Federal Fluminense (UFF). Trabalhou em organizações da sociedade civil, como a Brasil Foundation e o Centro de Ações Solidárias da Maré (CEASM). Coordenou a Comissão de Defesa dos Direitos Humanos e Cidadania da Assembleia Legislativa do Rio de Janeiro (ALERJ), ao lado de Marcelo Freixo. Mulher, negra, mãe (de uma estudante da UERJ), favelada... Foi a quinta vereadora (pelo PSOL) mais votada no Rio de Janeiro nas eleições de 2016, com 46.502 votos. Iniciou sua militância em direitos humanos após ingressar no pré-vestibular comunitário e perder uma amiga, vítima de bala perdida, num tiroteio entre policiais e traficantes no Complexo da Maré. Ao se tornar mãe aos 19 anos, de uma menina, Marielle também começou a se constituir como lutadora pelos direitos das mulheres e debater essa temática na periferia. As questões do feminismo, da luta contra o racismo, bem como a defesa dos direitos humanos nas favelas do país modulam o perfil de seu mandato e seus projetos em busca de um 


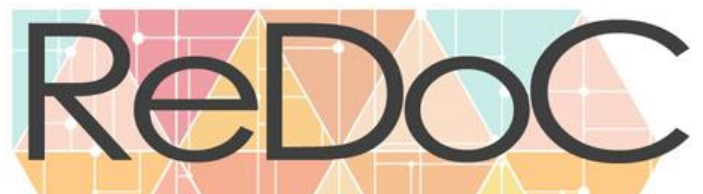

\section{Revista Docência e Cibercultura}

é um país estruturado pelo racismo (ALMEIDA, 2020), que permanece com as suas raízes fincadas no sistema escravocrata e expõe mulheres e homens negros, pobres e periféricos a situações desumanas de mais vulnerabilidade de adoecimento e morte. De acordo com o artigo Desigualdades raciais em saúde e a pandemia da covid-19 (2020), um dos estudos recentes que relaciona o aumento de mortes entre os negros por complicações respiratórias nesta pandemia ${ }^{6}$, nos remetendo a diversos processos de adoecimentos que esta população sofre ao longo dos séculos, "A pandemia desnuda o quanto o Brasil é um país desigual e pouco avançou na superação do racismo" (GOES; RAMOS; FERREIRA, 2020, p. 4).

Corpos que são sempre silenciados e até sufocados, metaforicamente ou até literalmente, como visto no caso de George Floyd ${ }^{7}$, o ex-segurança morto por asfixia após ter o pescoço prensado pelo joelho de um policial em Minneapolis, nos Estados Unidos. Suas últimas palavras foram "Eu não consigo respirar". No mesmo período, Cristiane Boneta ${ }^{8}$, esteticista em Duque de Caxias, na Baixada Fluminense-RJ, foi surpreendida, em uma consulta odontológica de rotina, ao ser "sufocada" (paramentada) com saco plástico preto para dar continuidade em seu tratamento dentário. O profissional que a atendeu alegou não ter uma touca cuja dimensão comportasse o seu cabelo. Por qual razão, então, haveria necessidade de usar um saco plástico sobre seu corpo se o problema era o cabelo da paciente? O racismo é estrutural e estruturante e desde sempre sufoca corpos negros (ALMEIDA, 2020).

Essas histórias reais nos remetem também à história da escritora mineira Carolina Maria de Jesus ${ }^{9}$, que viveu à margem (COLLINS, 2016), tendo uma vida sufocante. No entanto, seu Quarto de despejo foi talvez o único lugar que não a sufocou, apesar de toda a precariedade. Ela morreu em seu quarto, vítima de uma crise de insuficiência respiratória, doença que carregava desde o seu nascimento e que se agravou devido às péssimas condições de vida dela, as quais ela relata em alguns de seus livros. Moradia decente e saneamento básico: é pedir muito?

A asfixia à qual somos submetidos diariamente permanece nos adoecendo até a morte, como bem lembrou a professora, historiadora e intelectual negra Giovana Xavier, ao trazer a público (em uma $l_{i v e^{10}}$ ) o poema Tributo à Fênix Negra, de autoria desconhecida, publicado na dissertação da professora

modelo de cidade mais justo para todos e todas. Disponível em: 〈https://www.institutomariellefranco.org/>. Acesso em: 29 ago. 2021.

${ }^{6}$ No dia em que recebemos o aceite para publicação deste texto, também recebemos a triste notícia do falecimento de um amigo do ProPEd-UERJ por complicações em decorrência da COVID-19, Lindinalvo Natividade - Mestre Lindi, como o chamávamos carinhosamente no grupo de pesquisa, seu quilombo. Homem negro, Doutor em Educação, Professor de Educação Física da rede pública de Barra Mansa - RJ, Mestre de Capoeira do Centro Esportivo de Capoeira Quarto Crescente, Esposo da Ana e tantas outras coisas. Era o amor de muitos... Dedicamos este trabalho a ele, que após passar 28 dias internado, ao retornar para casa, teve uma enorme falta de ar seguida de um ataque cardíaco e não resistiu, assim como as mais de 579 mil pessoas. Segundo informações do Google Notícias sobre o coronavírus (COVID-19), até a data de envio final deste trabalho que coincide com a data de acesso, este é o total de mortes no Brasil. Disponível em: <https://news.google.com/covid19/map?hl=ptBR\&mid=\%2Fm\%2F015fr\&gl=BR\&ceid=BR\%3Apt-419>. Acesso em: 29 ago. 2021.

${ }^{7}$ Disponível em: < https://www.bbc.com/portuguese/internacional-57236428>. Acesso em: 29 de ago. 2021.

${ }^{8}$ Disponível em: < https://noticiapreta.com.br/tag/cristiane-boneta/>. Acesso em: 29 de ago. 2021.

${ }^{9}$ Disponível em: $<$ https://mundoeducacao.uol.com.br/literatura/carolina-maria-de-jesus.htm $>$. Acesso em: 29 ago. 2021.

${ }^{10}$ Quarentena com a Escola de História da UNIRIO. Aula 7 - Curso Emancipações e Pós-Abolição: por uma outra História do Brasil (1808-2020). Disponível em: < https://www.youtube.com/watch?v=XrEx-X4aa4U〉. Acesso em: 29 ago. 2021.

(c) Redoc Rio de Janeiro \begin{tabular}{l|l} 
v. 5 & ก. 3
\end{tabular} p. 34 Set./Dez. 2021 ISSN 2594-9004 


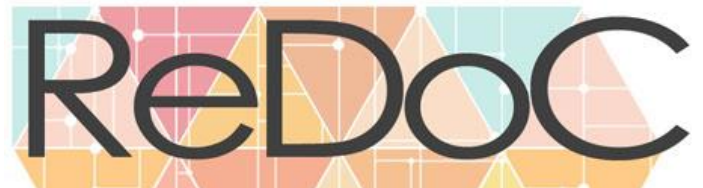

\section{Revista Docência e Cibercultura}

Claudete Alves (2008). Em todo o poema, é possível sentir a dor singular e coletiva da personagem: "Ela morreu de asfixia, cuspindo sangue por causa dos segredos que guardava tentando abafá-los em vez de se permitir a crise de nervos que lhe era de direito [...]" (p. 21). E assim tem sido com muitas de nós, principalmente em espaços de poder, como no caso de Marielle Franco. Ela - sua vida/seu corpo representa as pluralidades de fricções na sociedade, e o vídeo questiona esse processo de homogeneização que enaltece determinados corpos e marginaliza outros. Na performance apresentada em audiovisual, destacam-se os marcadores de gênero, raça, classe, sexualidade e geração, evidenciando as muitas redes educativas que um mesmo corpo ocupa e as muitas vozes que o atravessam.

\section{PRODUÇÃO AUDIOVISUAL}

Nós, através do audiovisual ${ }^{11}$, bem como neste trabalho, propomos uma produção ética, estética e política. Uma intervenção com figuras criadas para chocar e deslocar o corpo perfeito. Um corpo com armaduras da hegemonia se despedaçando e inaugurando sobre ele as alteridades de suas redes educativas. O roteiro foi elaborado como um "encontro" (PASSOS, 2014) entre o simbólico de Marielle Franco e a perspectiva de Paulo Freire, ou seja, a performance se passa num diálogo subjetivo entre esses dois personagens emblemáticos na atualidade. Esse corpo que aprendeensina e ao mesmo tempo é historicamente aprisionado, negado e excluído - tendo o direito de "existir" somente de forma subalternizada -, e está em busca da tão sonhada autonomia, porque até "morto" ele é perigoso. E por isso, ele permanece sendo injustiçado, culpabilizado e silenciado - tendo seus direitos negados mais ainda -, já tendo se passado 3 anos sem sabermos quem mandou matar Marielle (?).

Este corpo que só estampa as manchetes de jornais relacionados a questões de violência e morte, pois o mesmo não tem direito a vida, como nos mostra a filósofa pós-estruturalista estadunidense, Judith Butler (2015): "Se certas vidas não são qualificadas como vidas ou se, desde o começo, não são concebíveis como vidas de acordo com certos enquadramentos epistemológicos, então essas vidas nunca serão vividas nem perdidas no sentido pleno dessas palavras" (p. 13). A condição precária da vida nos impõe uma obrigação, devido ao nosso corpo estar exposto a forças articuladas social e politicamente. Afinal,

Nós não nascemos primeiro e em seguida nos tornamos precários; a precariedade é
coincidente com o próprio nascimento (o nascimento é, por definição, precário), o que
quer dizer que o fato de uma criança sobreviver ou não é importante, e que sua
sobrevivência depende do que podeŕamos chamar de uma "rede social de ajuda". É
exatamente porque um ser vivo pode morrer que é necessário cuidar dele para que
possa viver. Apenas em condições nas quais a perda tem importância o valor da vida
aparece efetivamente. [...] Essas populações são "perdíveis", ou podem ser
sacrificadas, precisamente porque foram enquadradas como já tendo sido perdidas ou
sacrificadas; são consideradas como ameaças à vida humana como a conhecemos, e
não como populações vivas que necessitam de proteção contra a violência ilegítima
do Estado, a fome e as pandemias. Consequentemente, quando essas vidas são
perdidas, não são objeto de lamentação, uma vez que, na lógica distorcida que

${ }^{11}$ Este vídeo, foi o trabalho final da disciplina Pensamento Pedagógico e 'espaçostempos' da escola e outras redes educativas - Cinema e Paulo Freire, do qual as autoras deste artigo fizeram parte, ministrada pelas professoras Conceição Soares e Nilda Alves, ofertada pelo Programa de Pós-graduação em Educação da Universidade do Estado do Rio de Janeiro (ProPEd-UERJ) em 2018; também apresentado em uma das atividades do mesmo Programa, em comemoração ao Centenário de Paulo Freire, os Círculos de Cultura (2021). Disponível em: < https://linktr.ee/circulosdecultura $>$. Acesso em: 29 ago. 2021.

\begin{tabular}{l|l|l|l|l|l|l|}
\hline (C Redoc & Rio de Janeiro & v. 5 & n. 3 & p. 35 & Set./Dez. 2021 & ISSN 2594-9004
\end{tabular}




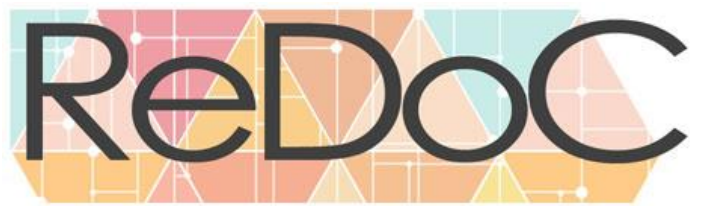

\section{Revista Docência e Cibercultura}

racionaliza sua morte, a perda dessas populações é considerada necessária para proteger a vida dos “vivos”. (BUTLER, 2015, p. 32 - 53).

A partilha sensível estará junto das epistemologias políticas e estéticas das visualidades, abrangendo os sentidos comuns e a particularidade que a cultura visual proporcionará ao telespectador. O filósofo francês Jacques Rancière (2009), assinala o entrelaçamento das manifestações sensíveis, a organização social e a ação artística do governo de si, tecendo formas que se confundem à invenção do inesperado. Da mesma forma que vemos os macros poderes se estenderem nas relações, temos no dia a dia uma intensa demanda política da sociedade nas trocas e embates visuais, e consideramos isto uma ação sensível da arte que está entrelaçada à política microbiana.

\section{MANIFESTO POÉTICO}

O pensamento crítico de Paulo Freire nos inspirou a escrever um manifesto poético, porque acreditamos que todas as linguagens artísticas e culturais são importantes, logo, formativas. Acreditando que nosso papel político deva ser expandido e potencializado pelo uso das tecnologias para alcançar o debate aberto, apostamos na força dialógica que o material pode proporcionar.

Que a nossa presença no mundo, implicando escolha e decisão, não seja uma presença neutra. A capacidade de observar, de comparar, de avaliar para, decidindo, escolher, com o que, intervindo na vida da cidade, exercemos nossa cidadania, se erige então como uma competência fundamental. Se a minha não é uma presença neutra na história, devo assumir tão criticamente quanto possível sua politicidade. Se, na verdade, não estou no mundo para simplesmente a ele me adaptar, mas para transformá-lo; se não é possível mudá-lo sem um certo sonho ou projeto de mundo, devo usar toda possibilidade que tenho para não apenas falar de minha utopia, mas para participar de práticas com ela coerentes. (FREIRE, 2000, p. 33).

Na tarefa social, política e ética de experimentar criticamente a leitura do mundo, percebemos as tramas sociais que constituem a produção de conhecimento. Paulo Freire em cartas que ousa ensinar deixou grandes indícios que a ousadia pedagógica busca outras formas de aprender com o discente. Entendemos que estar neste mundo envolve uma teia de significados, com suas urgências únicas e fundamentais de serem ouvidas para a democracia. O quão ousadas podemos ser? O choque visual desta produção estética buscou atender ao desconhecido sobre o tema trabalhado. Apenas um poema sobre um corpo e tantos outros significados para quem ousa ver.

Nesse sentido, o trabalho dialoga, principalmente, com a linguagem artística, sobretudo com o audiovisual, na busca incessante por uma nova linguagem que não nos desumanize, mas, muito pelo contrário, nos faça "[...] ganhar a voz, escrever e recuperar nossas histórias escondidas" (KILOMBA, 2019, p. 27), como sugere a filósofa e artista portuguesa Grada Kilomba (2019), que tem dado voz, corpo e imagem aos seus próprios textos. Tendo como premissa essa sugestão, o trabalho também contribui com as pesquisas em diálogo com os cotidianos, com seus praticantespensantes que tecem e articulam redes de conhecimentos e significações como pistas de suas ações/práticas, como forma de "literaturizar a ciência" (ALVES, 2001).

Ninguém é sujeito da autonomia de ninguém. De ninguém!

Por outro lado, ninguém amadurece de repente, aos 38 anos, como eu, 


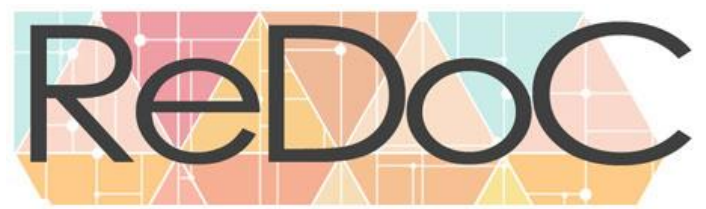

ou sei lá quantos anos você tem..

\section{Revista Docência e Cibercultura}

A gente vai amadurecendo todo dia (ou não?)

A autonomia enquanto amadurecimento do ser para si, é processo, é luta!

É vir a ser.

Eu sou porque nós somos... "Só somos porque estamos sendo. Estar sendo é a condição, entre nós, para ser” (p. 34). Eu sou porque nós somos!

Eu assumo: é nós por nós mesmos. Mas, “a assunção de nós mesmos, não significa a exclusão dos outros” (p.42). Eu sou porque nós somos!

Me forma, deforma, conforma.

Me excluem, incluem, excluem, por dentro e por fora

Vários gestos se cruzam cheios de significados (p.45)

- Me mataram hoje... Mentira! Me matam todos os dias: dia e noite, noite e dia

Eu tenho ensinado, eu tenho aprendido. Ensinar não é transferir conhecimento!

"O mundo não é. O mundo está sendo. [...] meu papel no mundo não é só de quem constata o que ocorre, mas também o de quem intervém como sujeito de ocorrências" (p. 74-75). Por isso, tentaram nos calar...

Tentaram nos enterrar, mas esqueceram que somos sementes

Eu tenho ensinado, eu tenho aprendido. Trocar é um ato político!

"Construir, reconstruir, constatar para mudar" (p.68), para melhorar, para ir além...

Foram 4 tiros... Minha cabeça dói, meu corpo para, olhos choram...

Muitos olhos choram. Lágrimas de dor escorrem pelo corpo

Sangue. Muito sangue! E, semente.

"Há perguntas a serem feitas insistentemente por todos nós e que nos

Fazem ver a impossibilidade de estudar por estudar" (p. 75):

Quem matou Marielle?

Quem matou Marielle?

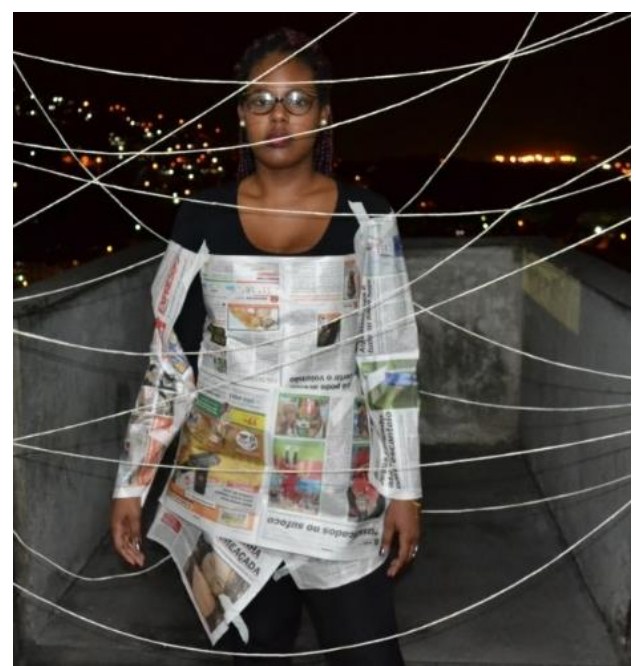

Figura 1. Manifesto poético através de uma performance audiovisual ${ }^{12}$

Fonte: Arquivo pessoal, 26 jun. 2018.

Iniciamos esse manifesto poético dizendo que "ninguém é sujeito da autonomia de ninguém" e terminamos perguntando "quem matou Marielle?", ou melhor dizendo: quem mandou matar Marielle e o motorista, Anderson Gomes?

\footnotetext{
${ }^{12}$ Making-Of da artista Cristiane Aparecida Fernandes de Jesus, protagonista da performance audiovisual filmada na Faculdade de Educação da UERJ. 


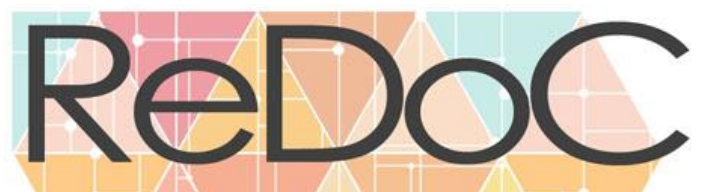

\section{Revista Docência e Cibercultura}

E como anunciado na proposta não juntaremos a nossa voz as práticas opressoras e seguiremos viabilizando a luta dos corpos em busca da autonomia - do direito à vida. Convidamos as leitoras e aos leitores deste artigo, que possam se juntar a nós e divulgar a comunidade científica da Educação, ou como propunha Paulo Freire, construir círculos de cultura de produção de saberes, como fortalecimento pedagógico do ato de ensinar, seja através do audiovisual (como fizemos) ou de formas outras com suas outras visões de mundo.

\section{CONSIDERANDO NOVAS FORMAS...}

No ano em que comemora-se o centenário de Paulo Freire, não há o que se comemorar. Estamos vivendo tempos difíceis, com um governo negacionista e genocida ${ }^{13}$, e há três anos temos perguntado: quem mandou matar Marielle Franco? A cibercultura teve um papel fundamental na difusão da demanda política relacionada à vida e morte de Marielle Franco e no centenário de Paulo Freire também. Nossa mobilização pelo audiovisual contempla a cibercultura das redes de conhecimentos. Muitas ideias podemos estender de uma obra estética, as possibilidades são infinitas como o uso tecnológico nos tempos atuais. Pois é importante assinalar que o acontecimento visto no audiovisual não se torna um acontecimento se não há a intromissão de novos olhares com diferentes sentidos. A intensidade das visualidades torna-se um contragolpe aos dispositivos paralisantes.

A escrita do pragmatismo cartesiano carrega marcas divisórias, enumerando-se traços físicos e sociais para descrever o sujeito. Desprezando ou diminuindo a sua expressividade e presença nos espaços que atravessa. O olhar hegemônico aprendido no mesmo dispositivo de controle nos cega para as pequenas conquistas cotidianas. Diante disso, para além da escrita e do olhar superficial, apresenta-se o cotidiano das sensações através da produção artística e cultural, que por sua vez, pode ser um meio eficaz à compreensão e/ou investigação crítica das realidades sociais que envolvem a luta política de Marielle Franco e Paulo Freire.

O desafio é a capacidade de sentir o corpo instintivo a cada desdobramento visual e auditivo, como propõe Paulo Freire em suas obras, mas especificamente na pedagogia da autonomia. O eu-corpo rasgasse das amarras sociais e provoca perfurações na sociedade ao caminhar em suas derivas de errância. Todo percurso do homem em busca da autonomia tem a emblemática insularidade cotidiana diante dos alicerces dominantes, errar por não se encaixar, talvez seja a maior rebeldia do corpo. A errância dá novos rumos e em seu desenvolvimento contínuo promove uma açãoreflexão sob o domínio. Enquanto os olhos se chocam nos erros, os errantes reconstroem seus espaçostempos.

Considerar a força da cibercultura através da difusão de práticas e ideias na atualidade, sobretudo neste período pandêmico - em face do cenário político devastador que temos vivenciado, as obras de Paulo Freire se faz mais do que nunca atual e necessário -, nos permite alcançar conhecimentos outros e valorizar novas formas de manifestações corporais, de ensinoaprendizagem, de produções artísticas e culturais, de ser e estar no mundo... Os pensamentos de Paulo Freire também nos ajudam a repensar nossa relação com o mundo, suas palavras são potências e nos apresenta um caminho: Tenhamos autonomia para rompermos com a opressão, pode ser que pelo caminho fique complicado colocar em prática todos os ensinamos deixados por Paulo Freire, no entanto, ao mesmo tempo pode ser que

${ }^{13}$ Disponível em: < https://pt.org.br/10-provas-do-genocidio-praticado-por-bolsonaro-durante-a-pandemia/> Acesso em: 29 ago. 2021. 


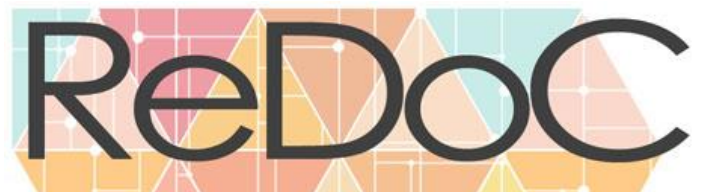

\section{Revista Docência e Cibercultura}

façamos mais que os seus desejos, criamos novos caminhos a partir de novas concepções e epistemologias que dialoguem com as demandas do tempo presente. A ideia de um corpo potente, político e que aprendeensina nos oportuniza sermos não apenas um, mas muitos - sementes.

\section{REFERÊNCIAS}

ALMEIDA, Silvio Luiz de. Racismo estrutural. São Paulo: Sueli Carneiro; Editora Jandaíra, 2020.

ALVES, Nilda Guimarães. Imagens de professoras e redes cotidianas de conhecimentos. Educar em Revista, Curitiba: Editora UFPR, n.24, 2004, p. 19-36.

ALVES, Nilda. Decifrando o pergaminho - o cotidiano na escola nas lógicas das redes cotidianas. In: OLIVEIRA, Inês Barbosa; ALVES, Nilda. Pesquisa no/do cotidiano das escolas - sobre redes de saberes. Rio de Janeiro: DP \& A, 2001.

BUTLER, Judith. Quadro de guerra. Quando a vida é passível de luto? Rio de Janeiro: Civilização Brasileira, 2015, p. 13-53.

COLLINS, Patrícia Hill. Aprendendo com a outsider within: a significação sociológica do pensamento feminista negro. In: Revista Sociedade e Estado, v. 31, n. 1, p. 99-127, jan./abr. 2016.

COURTINE, Jean-Jacques. Decifrar o corpo: pensar com Foucault. Petrópolis, Rj: Vozes, 2013.

FOUCAULT, Michel. Vigiar e punir: nascimento da prisão; tradução de Raquel Ramalhete. Petrópolis, vozes, 1987, 288p.

FREIRE, Paulo. Pedagogia da indignação: cartas pedagógicas e outros escritos. São Paulo: UNESP. 2000.

FREIRE, Paulo. Pedagogia da autonomia: saberes necessários à prática educativa. $44^{\mathrm{a}}$ ed. - Rio de Janeiro: Paz e Terra, 2013. ISBN: 978-85-7753-163-9.

GOES, Emanuelle Freitas; RAMOS, Dandara de Oliveira; FERREIRA, Andreia Jaqueline Fortes. Desigualdades raciais em saúde e a pandemia da Covid-19. In: Trabalho, Educação e Saúde, Rio de Janeiro, v. 18, n. 3, 2020, e00278110. DOI: 10.1590/1981-7746- sol00278.

GUMBRECHT, Hans Ulrich. Produção de presença - o que o sentido não consegue transmitir. Tradução de Ana Isabel Soares. Rio de Janeiro: Contraponto e PUC-Rio, agosto de 2010.

OLIVEIRA, Danielle Christina do Nascimento. Sobre a tessitura de redes de afetos: diálogos com mulheres negras da Baixada Fluminense. 2020. Dissertação (Mestrado em Educação) Faculdade de Educação, Programa de Pós-Graduação em Educação, Universidade do Estado do Rio de Janeiro, Rio de Janeiro, 2020.

PASSOS, Mailsa Carla Pinto. Encontros cotidianos e a pesquisa em Educação: relações raciais, experiência dialógica e processos de identificação. Educar em Revista, Curitiba: Editora UFPR, n. 51, jan./mar. 2014, p. 227-242.

RANCIÈRE, Jacques. A partilha do sensível: estética e política. São Paulo: Editora 34, 2.ed, 2009.

SILVA, Bianca de Menezes Castro da. Cotidiano das escolas: corpos em movimento, visualidades, sons, belezas e bagunça. 2020. Dissertação (Mestrado em Educação) - Faculdade de Educação, Programa de Pós-Graduação em Educação, Universidade do Estado do Rio de Janeiro, Rio de Janeiro, 2020.

SOUZA, Claudete Alves da Silva. A solidão da mulher negra: sua subjetividade e seu preterimento pelo homem negro na cidade de São Paulo. Dissertação (Mestrado em Ciências Sociais) Programa de Pós-Graduação da Pontifícia Universidade Católica de São Paulo, São Paulo, 2008.

KILOMBA, Grada. Memórias da plantação: episódios de racismo cotidiano. Rio de Janeiro: Cobogó, 2019.

Este é um artigo de acesso aberto distribuído sob os termos da Licença Creative Commons Atribuição Não Comercial-Compartilha Igual (CC BY-NC- 4.0), que permite uso, distribuição e reprodução para fins não comerciais, com a citação dos autores e da fonte original e sob a mesma licença. 